\title{
Cost-Effectiveness of Enhancing Primary Care Depression Management on an Ongoing Basis
}

\author{
Katbryn Rost, PbD \\ Jeffrey M. Pyne, $M D^{2}$ \\ L. Miriam Dickinson, $P b D^{1}$ \\ Anthony T. LoSasso, $\mathrm{PbD}^{3}$ \\ ${ }^{1}$ University of Colorado Health Sciences \\ Center, Aurora, Colo \\ ${ }^{2} \mathrm{HSR} \& \mathrm{D}$ Center for Mental Healthcare and \\ Outcomes Research and the Central Arkan- \\ sas Veterans Healthcare System, Department \\ of Psychiatry, University of Arkansas for \\ Medical Sciences, Little Rock, Ark \\ ${ }^{3}$ Division of Health Policy and Administra- \\ tion, School of Public Health, University of \\ Illinois at Chicago, Chicago, Ill.
}

Conflicts of interest: none reported

\section{CORRESPONDING AUTHOR}

Kathryn Rost, PhD

University of Colorado

Health Sciences Center

Department of Family Medicine

UCHSC at Fitzsimons

PO Box 6508, Mail Stop F496

Aurora, CO 80045-0508

Kathryn.Rost@UCHSC.edu

\begin{abstract}
PURPOSE Although potentially costly, enhancing primary care depression management on an ongoing basis results in substantial long-term treatment effectiveness. The purpose of this article is to compare the cost-effectiveness of this approach with that of usual care.

METHODS The study was conducted in 12 community primary care practices randomized to enhanced or usual care after stratification by baseline practice patterns. Practices assigned to enhanced care encouraged depressed patients to engage in active treatment, using practice nurses to provide regularly scheduled care management during the course of 24 months. We analyze outcomes for 211 adults (73.4\% of potential eligible patients) beginning a new treatment episode for major depression determined by previsit screening. Outcomes included blinded estimates of days free of depression impairment as well as health care costs for 2 years.
\end{abstract}

RESULTS Enhanced care significantly increased the number of days free of depression impairment for 2 years when compared with usual care (647.6 days vs 588.2 days, $P<.01)$. The incremental cost-effectiveness ratio for enhanced care ranged from $\$ 9,592$ to $\$ 14,306$ per quality-adjusted life-year (QALY). The number of incremental days free of depression impairment increased between the first year and the second year $(23.0$ vs 36.4 , respectively, $P<.001)$ while incremental health plan costs decreased significantly ( $\$ 568$ vs $-\$ 12, P<.001$ ).

CONCLUSIONS Enhancing primary care depression management on an ongoing basis should be considered for adoption by policy and health plan leaders.

Ann Fam Med 2005;3:7-14. DOI: 10.1370/afm.256

\section{INTRODUCTION}

$\mathrm{D}$ epression is a leading cause of disability in developed nations. ${ }^{1}$ Most primary care depression programs designed to improve acute depression management last 6 months or less. ${ }^{2-22}$ Because brief programs have little to no sustained effect 1 year after termination, ${ }^{21-24}$ we tested a model that enhances primary care depression management on an ongoing basis. By supplementing acute management ${ }^{25}$ with systematic monitoring for 24 months, this model incorporates chronic disease management principles ${ }^{26,27}$ and results in clinically significant improvements in both symptoms and functioning at 2 years. ${ }^{28}$ Given the clinical effectiveness at modest cost, we hypothesized that enhancing primary care depression management on an ongoing basis would be cost-effective when compared with usual care. Although it is premature to draw definitive conclusions when comparing the relative costs of brief and ongoing models of care, evidence of the cost-effectiveness of ongoing models provides important new information about the value of extending the brief programs currently being disseminated. ${ }^{29}$ 
Because the model we tested did not improve clinical outcomes in patients who entered the study depressed despite recent treatment, ${ }^{30}$ we reasoned that health care managers interested in this model would target it to patients who benefited, eg, patients beginning a new depression treatment episode. Thus, we conducted a post hoc analysis of randomized trial data drawn from patients beginning a new depression treatment episode.

\section{METHODS}

\section{Experimental Design and Sample}

Our methods, described in detail elsewhere, ${ }^{25}$ are summarized here. After approval by the Human Research Advisory Committee of the University of Arkansas for Medical Sciences and the Colorado Multi-Institutional Review Board, the research team conducted the study in 12 community primary care practices across the United States, none of which employed onsite mental health professionals to treat depression. The first author matched the 12 practices into 6 blocks by depression treatment patterns, and 1 practice from each block was randomly assigned to enhanced care. Patients coming in for routine visits at these practices between April 1996 and September 1997 were asked to complete a 2-stage screening instrument. Patients eligible for the study reported 5 or more of the 9 Diagnostic and Statistical Manual of Mental Disorders: DSM-III-R ${ }^{31}$ criteria for major depression in the preceding 2 weeks. Excluded from the study were eligible patients who met criteria for bereavement, mania, alcohol dependence, pregnancy or postpartum, or life-threatening physical illness; patients who did not intend to use the clinic as their usual source of care in the next year; patients who did not have telephone access; patients who were illiterate in English; or patients who were cognitively impaired. For this analysis, we also excluded depressed patients in treatment at baseline.

\section{Enhanced Care}

Before patient enrollment, the research team provided brief training ${ }^{25}$ to primary care professionals in enhanced care practices to implement a care management system to improve acute and continuation phase treatment for patients with major depression. Training emphasized that physicians and care managers encourage patients to initiate guideline-concordant pharmacotherapy or psychotherapy through regularly scheduled contacts during the acute phase of treatment. ${ }^{30}$ Training also emphasized that physicians and care managers make regularly scheduled contacts to encourage continued treatment adherence when symptoms were resolving, to adjust treatment if symptoms were not resolving, and to terminate treatment when patients in remission did not require maintenance therapy after the continuation phase of care. ${ }^{28}$ Care managers reached $95.7 \%$ of 115 patients in enhanced care practices during the 24 months of the study, for an average of 11.8 contacts $(\mathrm{SD}=5.9)$ per patient. Usual care practices were not systematically informed about which patients were participating in the study.

\section{Data Collection}

As displayed in Figure 1, 653 of 11,006 patients had positive screening results for depression on the 2-stage screening instrument and met study criteria for enrollment. Of these patients, $73.4 \%$ (479 of 653) agreed to further evaluation, and $44.0 \%$ (211 of 479 ) were beginning a new treatment episode for major depression. After screening, all data were collected during a structured telephone interview by an independent research interviewer. The interviewer was unaware of whether the patient was receiving enhanced treatment or usual care, except for 3 patients whose practices were contacted for updated location information. Concordant with an intent-to-treat design, patients who left the practice were interviewed again even though they could not continue to participate in ongoing intervention. Follow-up interviews at 6, 12, 18, and 24 months conducted by the research interviewer between October 1996 and September 1999 achieved response rates of $89.6 \%, 81.5 \%, 72.5 \%$, and $67.3 \%$, respectively.

\section{Operational Definition of Major Constructs Quality-Adjusted Life-Years}

We evaluated the impact of the program on days free of depression impairment by asking patients to estimate the number of days during the past 4 weeks that their emotional problems kept them in bed all or most of the day or caused them to cut down on activities they usually do for 1 half-day or more. We estimated the impact of the model on quality-adjusted life-years (QALYs) by assuming that each depression impairment-free day improved QALYs by .00082 (.3/365), consonant with estimates in the literature that patients realize a .2 to .4 decline in QALYs with 365 days of depression. ${ }^{32-35}$ We also estimated the impact of the program on generic measures of QALYs. A description of the analysis is available online only as supplemental data in the Appendix ${ }^{36-42}$ which can be found at: http://www. annfammed.org/cgi/content/full/3/1/7/DC1 .

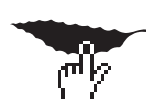

Costs

We assumed an accounting perspective ${ }^{43}$ to estimate the cost of enhanced care to society and to health care plans. To describe its cost to society in the health care environment in which it was tested (nonadjusted cost), we estimated the difference between enhanced and 
usual care in actual program costs, outpatient costs, and patient time and transportation costs for 2 years; for its cost to health care plans, we estimated the difference between enhanced and usual care in actual program and outpatient treatment costs for 2 years. To describe its effect in the 2007 health care environment, when commonly prescribed antidepressant medications are expected to cost considerably less than they do today (medication-adjusted costs), we estimated outpatient treatment costs using generically priced selective serotonin reuptake inhibitors.

Cost data were log-transformed to approximate normal distributions before analysis, and retransformed

\section{Figure 1. Patient recruitment and participation flowchart.}

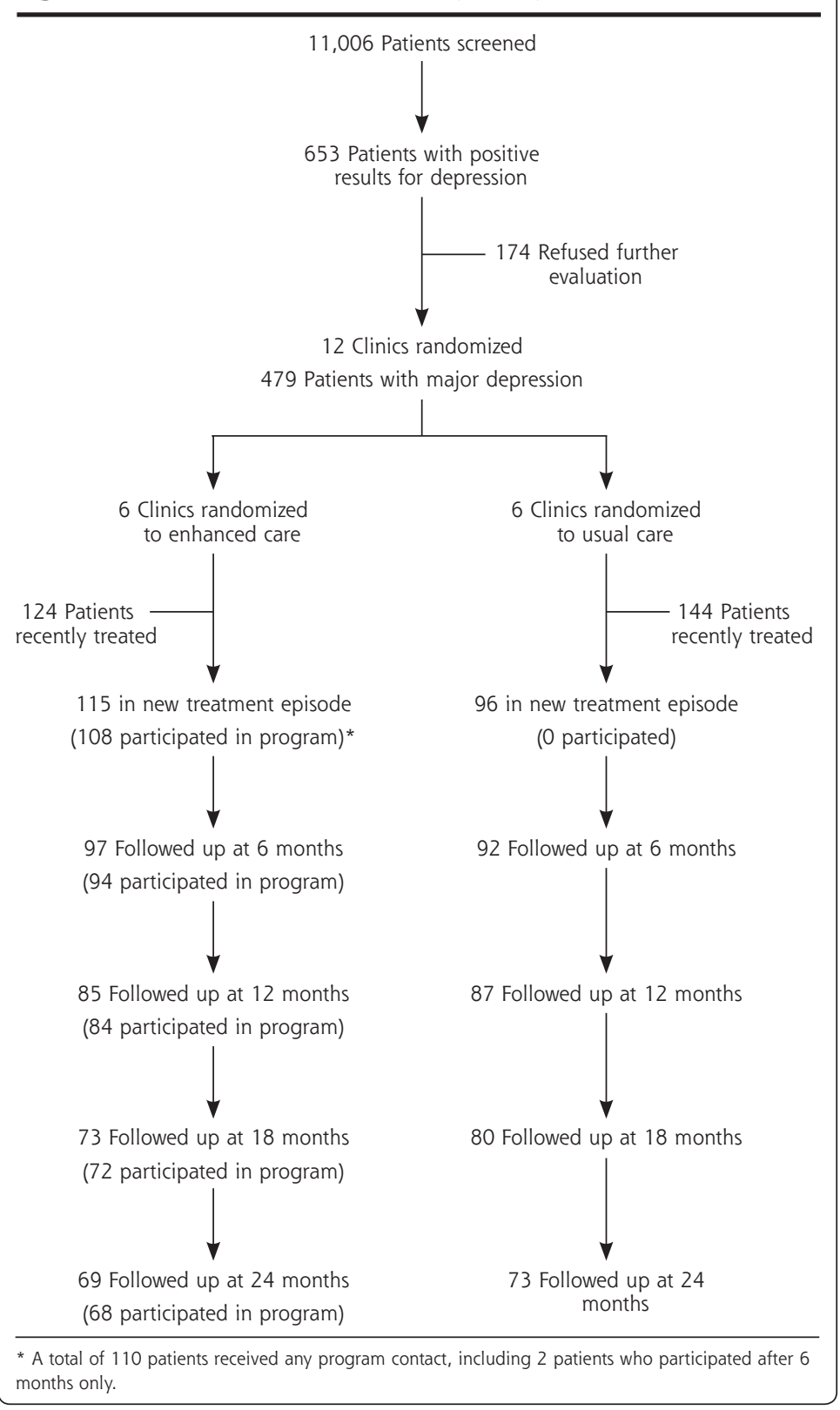

using appropriate smearing retransformations. ${ }^{44,45}$ All costs reported in this article (for our study and other studies) have been adjusted by the Consumer Price Index adjustment ${ }^{46}$ to reflect 2000 US dollars.

Program costs included time costs (salary plus fringe benefits) derived from care manager logs for patient screening, preparation for and delivery of enhanced care, record keeping and review, and care managerphysician communication plus overhead. Our annual per capita model cost estimates, summarized in Table 1, differ slightly from our estimates in Table 2, reflecting the uncertainty introduced in the transformationretransformation process of modeling costs.

Outpatient Costs. Similar to previous studies, ${ }^{32}$ outpatient costs for primary care and specialty mental health care visits, emergency department visits, and psychotropic medication were estimated from patient-reported utilization at each wave, reflecting that patients were insured by 65 different health plans or uninsured. Outpatient visit costs were estimated using 1999 Medicare payment rates. Emergency department visit costs were estimated at $\$ 500$ per episode. For the nonadjusted cost estimate, psychotropic medication costs were priced at the lowest average generic wholesale price per medication dosage reported in the 2000 Red Book $k^{47}$ of prescription drugs. For the medication-adjusted cost estimate, fluoxetine, sertraline, and paroxetine were priced at $\$ 0.50$ per dose. Like other cost-effectiveness analyses of primary care depression models, ${ }^{2,4,10}$ we did not include (1) inpatient costs, because we did not observe between-group differences in hospitalization, which affected only a small proportion of patients; and (2) productivity costs, often attributed to the nonmonetized denominator in the cost-effectiveness ratio, ${ }^{37}$ the exclusion of which results in a conservative estimate of the cost-effectiveness of the model from a societal perspective.

\section{Patient Time and Transportation} Costs. Time costs were estimated from patient reports of travel times to and from the clinic plus waiting time. For employed patients, time costs were calculated using self-reported wage rates. For unemployed patients, we substituted year 2000 average wage rates by gender and education as a proxy of patient time costs. Transportation costs were calculated from patient- 


\begin{tabular}{|c|c|c|c|}
\hline Activity & Time & $\begin{array}{c}\text { Cost per } \\
\text { Hour } \\
\$\end{array}$ & $\begin{array}{c}\text { Mean per } \\
\text { Capita Cost } \\
\$\end{array}$ \\
\hline Office assistant screening & $\begin{array}{l}.050 \mathrm{hr} \text { per screening test } \times 5,838 \\
\text { screening tests } / 115^{*}\end{array}$ & 13.91 & 35.28 \\
\hline Care manager preparation & $.115 \mathrm{hr}$ per contact $\times 11.8$ contacts & 24.40 & 33.11 \\
\hline Care manager contacts & $.210 \mathrm{hr}$ per contact $\times 11.8$ contacts & 24.40 & 60.46 \\
\hline $\begin{array}{l}\text { Care manager record } \\
\text { keeping }\end{array}$ & $.165 \mathrm{hr}$ per contact $\times 11.8$ contacts & 24.40 & 47.51 \\
\hline $\begin{array}{l}\text { Physician review of care } \\
\text { manager's records }\end{array}$ & $.550 \mathrm{hr}$ & 85.51 & 47.03 \\
\hline $\begin{array}{l}\text { Care manager communication } \\
\text { with physician }\end{array}$ & $.216 \mathrm{hr}$ & 24.40 & 5.27 \\
\hline $\begin{array}{l}\text { Physician communication } \\
\text { with care manager }\end{array}$ & $.216 \mathrm{hr}$ & 85.51 & 18.47 \\
\hline Overhead & $30 \%$ of above costs & & 74.14 \\
\hline 2-year total costs & & & 321.27 \\
\hline Annual costs & & & 160.64 \\
\hline \multicolumn{4}{|c|}{$\begin{array}{l}\text { Note: Screening by office assistant, care manager, and physician cost per hour derived from Bureau of Labor Statis- } \\
\text { tics estimate for median office assistant, registered nurse, and general/family practitioner earnings plus } 25 \% \text { fringe } \\
\text { benefits inflated to year } 2000 \text { dollars. Office assistant, care manager, and physician time estimates derived from care } \\
\text { management report. }\end{array}$} \\
\hline \multicolumn{4}{|c|}{ *Identifying 115 patients beginning a new treatment episode required screening 5,838 patients. } \\
\hline
\end{tabular}

Table 2. Enhanced Care Impact on Incremental Costs by Category and Year $(n=211)$

\begin{tabular}{|c|c|c|c|}
\hline Costs & $\begin{array}{c}\text { Year } 1 \\
\text { Mean \$ }(95 \% \mathrm{Cl})\end{array}$ & $\begin{array}{c}\text { Year } 2 \\
\text { Mean } \$(95 \% \mathrm{Cl})\end{array}$ & $\begin{array}{c}\text { Total } \\
\text { Mean \$ }(95 \% \mathrm{Cl})\end{array}$ \\
\hline Program & 158 (147 to 169$)$ & 130 (120 to 140$)$ & 288 (267 to 309) \\
\hline \multicolumn{4}{|l|}{ Outpatient } \\
\hline Nonadjusted & 410 (395 to 425 ) & $-142(-162$ to -122$)$ & 268 (233 to 303 ) \\
\hline Medication adjusted & 225 (211 to 238$)$ & $-188(-203$ to -173$)$ & 37 (8 to 65) \\
\hline $\begin{array}{l}\text { Patient time and } \\
\text { transportation }\end{array}$ & 107 (103 to 111$)$ & 38 (34 to 42$)$ & 145 (137 to 153$)$ \\
\hline \multicolumn{4}{|l|}{ Total } \\
\hline Nonadjusted & 675 (645 to 705$)$ & $26(-8$ to 60$)$ & 701 (637 to 765) \\
\hline Medication adjusted & 490 (461 to 518 ) & $-20(-49$ to 9$)$ & $470(412$ to 527$)$ \\
\hline
\end{tabular}

Note: Medication-adjusted costs refer to estimates of outpatient costs when fluoxetine, sertraline, and paroxetine become available for generic price of $\$ .50$ per dose.

$\mathrm{Cl}=$ confidence interval.

reported round-trip miles to and from the location of services at a rate of $\$ 0.325$ per mile.

Cost-Effectiveness Ratio. The numerator in the cost-effectiveness ratio is the incremental difference in cost between enhanced and usual care. The denominator is the incremental difference in QALYs between enhanced and usual care. Costs and QALYs were not discounted, because costs and benefits accrue concurrently during the short time horizon of the study.

\section{Data Analysis}

We conducted intent-to-treat analyses controlling for clinical and sociodemographic covariates using all available data to evaluate the incremental effect (enhanced minus usual care) of enhanced care on depression impairment-free days and cost using the perspective of a typical patient in our sample (see the Appendix). When these models indicated enhanced care had a significant impact on both outcomes and cost, we used a bootstrap method ${ }^{48,49}$ across 1,000 replications (1) to generate the distribution of QALY, costs, and cost-effectiveness ratios with nonparametric confidence intervals; and (2) to construct dominance plots and acceptability curves ${ }^{50}$ to describe the distribution of enhanced care cost-effectiveness in the current health care environment.

\section{RESULTS}

\section{Study Participants}

On average, the 211 patients participating in the study were 43.1 years old $(\mathrm{SD}=14.8$ years), with $84.4 \%$ female, $15.6 \%$ minority, $47.4 \%$ currently married, $79.2 \%$ high school educated, $62.1 \%$ employed full-time or part-time, and $82.5 \%$ with health insurance. These patients had an average of 2.1 physical comorbidities. Clinically, they reported an average of 6.4 DSM-III-R depression criteria in the preceding 2 weeks, $10.0 \%$ met criteria for dysthymia in the past year, and $73.3 \%$ reported a previous episode of depression. Enhanced and usual care patients were comparable except for small but statistically significant differences in age, depression severity, and physical comorbidity, which were controlled for by covariates in the model (described in the Appendix).

\section{Enhanced Care Effects on QALYs}

As displayed in Figure 2, there were significantly more days free of depression impairment during the 2 years for enhanced care patients than for usual care patients (647.6 days vs 588.2 days, $P<.01)$. In the bootstrap sample, enhanced care increased incremental days free of depression impairment during the 2 years by 59.4 days ( $95 \%$ confidence interval $[\mathrm{CI}], 38.0-80.7)$, with enhanced care 
Figure 2. Enhanced care effect on outcomes $(n=211)$.

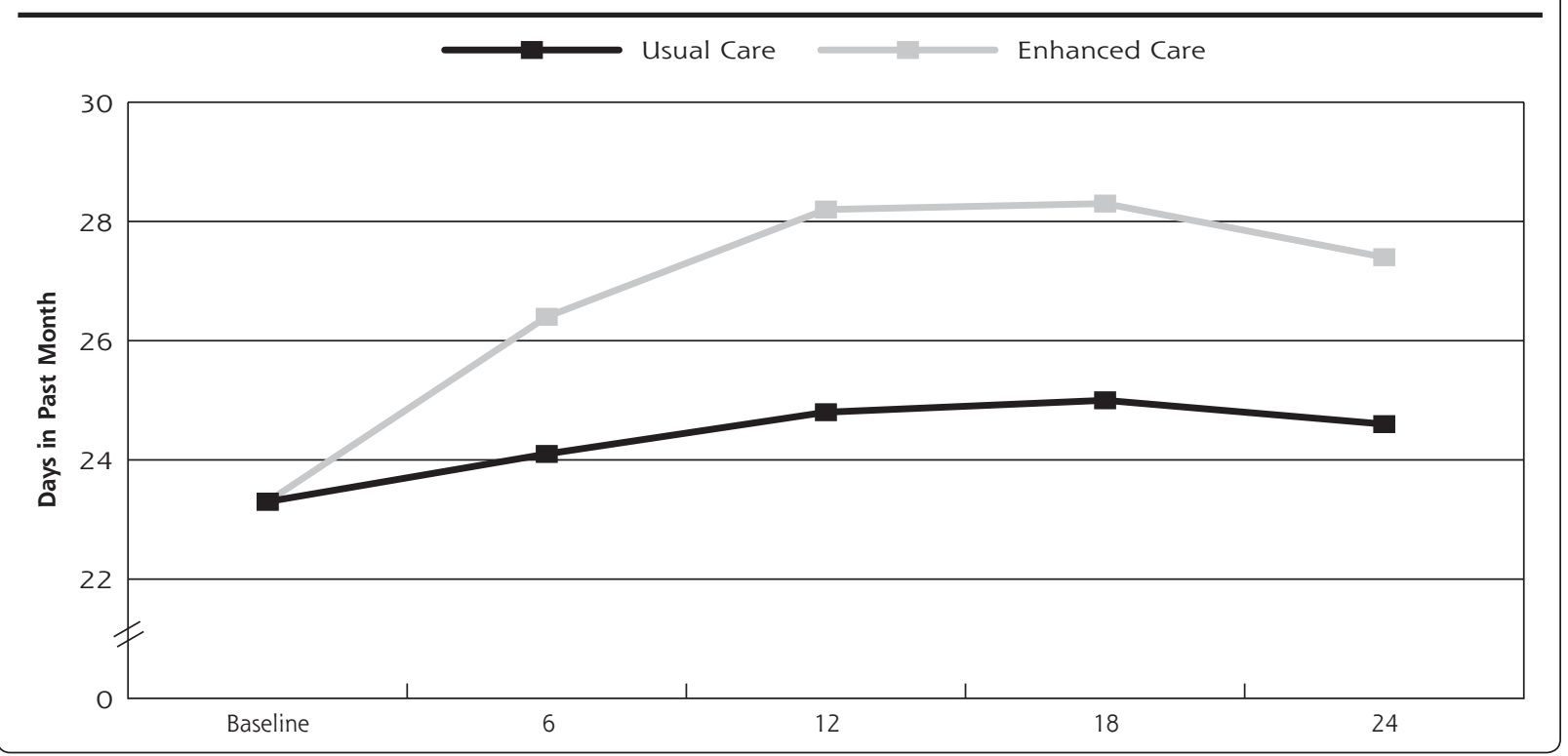

patients reporting significantly more incremental days free of depression impairment in the second year than in the first (36.4 days and 23.0 days, respectively, $P<.001$ ). Translating these effects to quality of life, the impact of enhanced care on depression-specific QALYs relative to usual care for the 2 years was 0.049 .

\section{Enhanced Care Effects on Costs}

Table 2 displays the impact of enhanced care on costs by category and year. Total nonadjusted costs (program, outpatient, and patient time and transportation costs) increased by $\$ 701$ more than usual care $(95 \%$ $\mathrm{CI}, \$ 637-\$ 765, \mathrm{~F}=6.82, P>.001, d f=4,198)$. The effect of enhanced care on total nonadjusted costs was significantly greater in the first year than in the second ( $\$ 675$ vs $\$ 26$, respectively, $P<.001$ ). Health plan nonadjusted costs (program and outpatient costs) increased by $\$ 556$ more than usual care $(95 \% \mathrm{CI}$, $\$ 500-\$ 612, F=7.46, P<.001, d f=4,198)$. The effect of enhanced care on health plan nonadjusted costs was significantly greater in the first year than in the second ( $\$ 568$ vs $-\$ 12$, respectively, $P<.001)$, indicating reduced health care utilization from enhanced care was sufficient to pay for its cost the second year. Total medication-adjusted costs increased by $\$ 470$ more than usual care $(95 \% \mathrm{CI}, \$ 412-\$ 527, \mathrm{~F}=6.23$, $P<.001, d f=4,198)$, and health plan medicationadjusted costs increased by $\$ 325$ more than usual care (95\% CI, \$275-\$374, $\mathrm{F}=6.86, P<.001, d f=4,198)$.

\section{Cost-Effectiveness Ratios}

The bootstrap analysis indicated that the mean incremental cost-effectiveness ratio for enhanced care ranges from $\$ 9,592$ (medication-adjusted costs) to $\$ 14,306$ (nonadjusted costs) per QALY. Dominance plot analysis showed that $88.7 \%$ of patients would be expected to have improved outcomes with increased costs, and $11.3 \%$ of patients would have improved outcomes with decreased costs. Acceptability curve analysis showed that the mean incremental cost-effectiveness ratio had a $100 \%$ probability of being less than $\$ 20,000$ per QALY in all analyses.

\section{DISCUSSION}

Consistent with its sustained effectiveness, ${ }^{28}$ the costeffectiveness ratio for improving primary care depression management for 2 years in this population ranges from $\$ 9,592$ to $\$ 14,306$ per QALY, slightly less than our first-year estimate. ${ }^{51}$ This analysis shows that incremental QALYs significantly increase with time while incremental costs decline, providing the first evidence that depression disease management can become more effective and less costly with time. We suspect we observed increasing QALYs because enhanced care improved role functioning until it reached nearly normal levels at 2 years. ${ }^{28}$ Improved functioning may have, in turn, caused or been simultaneous with a reduction in outpatient costs sufficient to cover modest program costs, as we observed in the second year.

Although direct comparisons cannot be made with previous primary care depression trials that use varying strategies to measure cost-effectiveness in clinically different populations (Table $3^{2,4,10,33,34}$ ), enhanced care management on an ongoing basis appears to be a particularly promising use of health care resources. This conclusion 


\begin{tabular}{|c|c|c|c|c|c|c|}
\hline Study & $\begin{array}{l}\text { Unique } \\
\text { Characteristics } \\
\text { of Sample }\end{array}$ & $\begin{array}{l}\text { Depression-Specific } \\
\text { QALY Measure }\end{array}$ & Cost Measure & $\begin{array}{l}\text { Annual } \\
\text { Costs* } \\
\$\end{array}$ & $\begin{array}{l}\text { Outcome }^{\dagger} \\
\text { d/y }\end{array}$ & $\begin{array}{l}\text { Duration } \\
\text { of Analysis } \\
\text { Months }\end{array}$ \\
\hline Katon et $\mathrm{al}^{2}$ & $\begin{array}{l}\text { Beginning } \\
\text { antidepressant } \\
\text { treatment }\end{array}$ & $\begin{array}{l}\text { SCL derivation of } \\
\text { depression-free days }\end{array}$ & $\begin{array}{l}\text { Outpatient costs } \\
\text { Program costs not included }\end{array}$ & 467 & 15.8 & 6 \\
\hline Katon et $\mathrm{al}^{4}$ & $\begin{array}{l}\text { Beginning } \\
\text { antidepressant } \\
\text { treatment }\end{array}$ & $\begin{array}{l}\text { SCL derivation of } \\
\text { depression-free days }\end{array}$ & $\begin{array}{l}\text { Outpatient costs } \\
\text { Program costs not included }\end{array}$ & 575 & 13.4 & 6 \\
\hline \multirow[t]{2}{*}{ Lave et $\mathrm{al}^{33}$} & Medication (M) & \multirow{2}{*}{$\begin{array}{l}\text { Hamilton and Beck } \\
\text { derivation of } \\
\text { depression-free days }\end{array}$} & \multirow{2}{*}{$\begin{array}{l}\text { Program and training costs; } \\
\text { inpatient and outpatient costs; } \\
\text { patient time and transportation }\end{array}$} & $1,701(\mathrm{M})$ & 58.0 & \multirow[t]{2}{*}{12} \\
\hline & Therapy $(\mathrm{T})$ & & & $1,994(\mathrm{~T})$ & 49.0 & \\
\hline Simon et a $1^{10}$ & $\begin{array}{l}\text { Beginning } \\
\text { antidepressant } \\
\text { treatment }\end{array}$ & $\begin{array}{l}\text { SCL derivation of } \\
\text { depression-free days }\end{array}$ & $\begin{array}{l}\text { Outpatient costs } \\
\text { Program costs not included }\end{array}$ & 149 & 12.6 & 6 \\
\hline \multirow[t]{3}{*}{ Simon et al ${ }^{34}$} & \multirow[t]{3}{*}{ High utilizers } & \multirow{3}{*}{$\begin{array}{l}\text { Hamilton derivation of } \\
\text { depression-free days }\end{array}$} & Program costs; outpatient costs & 1,008 & \multirow[t]{3}{*}{47.4} & \multirow[t]{3}{*}{12} \\
\hline & & & $\begin{array}{l}\text { Program costs; inpatient and } \\
\text { outpatient costs }\end{array}$ & 1,974 & & \\
\hline & & & $\begin{array}{l}\text { Program costs; inpatient and } \\
\text { outpatient costs; patient time }\end{array}$ & 2,475 & & \\
\hline $\begin{array}{l}\text { Hargreaves } \\
\text { et al }\left.\right|^{\ddagger}\end{array}$ & $\begin{array}{l}\text { Beginning } \\
\text { antidepressant } \\
\text { treatment }\end{array}$ & $\begin{array}{l}\text { Hamilton derivation of } \\
\text { depression-free days }\end{array}$ & $\begin{array}{l}\text { Program costs; inpatient and } \\
\text { outpatient costs }\end{array}$ & 307 & 12.3 & 6 \\
\hline Current study & & $\begin{array}{l}\text { Direct report of } \\
\text { depression } \\
\text { impairment-free days }\end{array}$ & $\begin{array}{l}\text { Program costs; outpatient costs; } \\
\text { patient time and transportation }\end{array}$ & 350 & 29.7 & 24 \\
\hline
\end{tabular}

is compatible with published observations that the clinical improvement associated with brief programs declines with time, ${ }^{24,35}$ whereas the clinical improvement associated with ongoing management increases with time. ${ }^{28}$

This debate over brief vs ongoing management models should not obscure the recognition that costeffectiveness ratios associated with both models suggest improving primary care depression management is a good value and results in comparable or greater cost-effectiveness than smoking cessation counseling (>\$8,000 per QALY), hypertension pharmacotherapy (>\$14,000 per QALY), hypercholesterolemia pharmacotherapy ( $\$ 18,000$ per QALY), chronic obstructive pulmonary disease rehabilitation ( $>36,000$ per QALY), or depression screening alone $(>\$ 45,000) .{ }^{52-54}$

While encouraging cost-effectiveness ratios are useful in convincing policy makers that providing high-quality primary care depression treatment is an efficient use of health care resources, they may be less helpful in elucidating which stakeholder group (purchasers, plans, or patients) should underwrite program and incremental treatment costs. These data suggest if purchasers did not contribute any additional monies for enhanced depression management, plans with access to multiple generically priced antidepressants would spend
$\$ 383(\$ 158+\$ 225)$ the first year and save $\$ 58(\$ 130$ - $\$ 188$ ) the second year by providing ongoing management to each depressed participant. Plans may be able to pass a portion of these costs on to their patients, as depressed patients report being willing to pay an average of $\$ 1,620$ for a 6 -month treatment that eliminates all symptoms of depression. ${ }^{55}$

The internal validity of our findings is strengthened by a randomized block design to evaluate the impact of enhanced care on the outcomes and costs of care using an intent-to-treat analysis. Our conclusions about costeffectiveness are strengthened by the convergence of estimates derived from depression-specific and generic QALY measures (see the Appendix). To address recently released recommendations to evaluate the impact of the intervention on functional status, ${ }^{56}$ we selected a depression-specific QALY measure that captured depressive symptoms severe enough to reduce functioning, recognizing that patients in both the enhanced and usual care condition may have additional days of milder symptoms than our measure captured. Because the 3 measures of depression-free days currently in use (Table 3) conceptually and statistically overlap to varying degrees, we encourage future researchers to reach consensus on a brief and valid measure of depression-specific QALYs. 
Doing so will increase opportunities to compare program results across large effectiveness trials. Our cost estimates for the as-planned program ${ }^{25}$ are slightly higher than our actual cost estimates for the as-delivered program, because enhanced care patients did not participate in all the contacts offered. Fielding the study in practices caring for patients insured through multiple health plans forced us to rely on patient reports to measure outpatient costs. Relying on patient-reported health care use introduces measurement imprecision; however, it should not bias the study findings on incremental costs. Regarding our exclusion of nonpsychotropic medication (which is not available in the data set), we note that similar efforts to improve depression treatment have not had a significant impact on these costs, ${ }_{1}^{57}$ so we do not anticipate that excluding them from cost-effectiveness estimates seriously biased our results. Regarding our decision to exclude hospitalization costs, we encourage researchers to derive cost-effectiveness ratios including hospitalization costs in preplanned meta-analysis of multiple large trials, because hospitalizations are too infrequent an event in any single trial to estimate their contribution to incremental costs with any precision.

The generalizability of our findings is strengthened because the program was implemented by health care professionals practicing in organizationally heterogeneous clinics across the country under naturalistic conditions where physicians and diverse patients were free to select the treatments they preferred. We attempted to reduce the impact of sample loss so it was similar to or smaller than that of most studies of this kind ${ }^{24}$ by using modeling techniques that allowed us to project trends when patients did not complete all follow-up interviews. We emphasize that our results are limited to primary care patients beginning a new treatment episode for depression (about $44 \%$ of depressed patients visiting a practice), because our previous research shows that this approach is not effective for depressed patients receiving depression care at baseline. ${ }^{30} \mathrm{We}$ encourage further research that tests approaches which increase specialty care consultation or collaboration ${ }^{2,58}$ for this potentially treatment-resistant cohort.

To read or post commentaries in response to this article, see it online at http://www.annfammed.org/cgi/content/full/3/1/7.

Key words: Cost-effectiveness; cost-benefit analysis; depression; quality of life; primary care; mental health

Submitted March 19, 2004; submitted, revised, June 1, 2004; accepted June 7, 2004.

Funding support: This project was supported by the National Institute of Mental Health MH54444 and MH63651, and the MacArthur Foundation. Dr. Pyne's contributions were supported by a VA Research Career Development Award and the VISN 16 MIRECC.
Acknowledgments: The authors wish to acknowledge the physicians, office staff, and patients of participating primary care practices: Chatham Primary Care, Siler City, NC; Dunes Family Health Care, Reedsport, Ore; Eau Claire Family Medicine, Eau Claire, Wisc; Enid Family Medicine Clinic, Enid, Okla; Fergus Falls Medical Group, Fergus Falls, Minn; Health East Eastside Medical Center, St. Paul, Minn; Lynchburg Family Practice, Lynchburg, Va; Mile Bluff Clinic, Mauston, Wisc; Mountain Area Family Health, Asheville, NC; Northern Colorado Family Medicine, Greeley, Colo; Oakwood Health Care Center, Westland, Mich; Somerset Family Practice, Somerville, NJ; and University of North Dakota Center for Family Medicine, Minot, ND. We are extremely grateful to our colleagues in the Depression Guidelines Study, the Quality in Depression (QID) Cooperative Agreement, and research staff from the Center for Outcomes Research and Evaluation for the superb technical assistance and encouragement they offered.

\section{References}

1. Murray C, Lopez A, eds. The Global Burden of Disease: A Comprehensive Assessment of Mortality and Disability from Diseases, Injuries, and Risk Factors in 1990 and Projected to 2020. Boston: The Harvard School of Public Health on Behalf of the World Health Organization and the World Bank; 1996.

2. Katon W, Von Korff M, Lin E, et al. Collaborative management to achieve treatment guidelines: impact on depression in primary care. JAMA. 1995;273:1026-1031.

3. Mynors-Wallis LM, Gath DH, Day A, Baker F. Randomised controlled trial of problem solving treatment, antidepressant medication, and combined treatment for major depression in primary care. $B M J$. 2000;320:26-30.

4. Katon W, Robinson P, Von Korff M, et al. A multifaceted intervention to improve treatment of depression in primary care. Arch Gen Psychiatry. 1996;53:924-932

5. Schulberg HC, Block MR, Madonia MJ, et al. Treating major depression in primary care practice: eight-month clinical outcomes. Arch Gen Psychiatry. 1996:53:913-919.

6. Wells KB, Sherbourne CD, Schoenbaum M, et al. Impact of disseminating quality improvement programs for depression in managed primary care: a randomized controlled trial. JAMA. 2000;283:212-220.

7. Mynors-Wallis LM, Gath DH, Lloyd-Thomas AR, Tomlinson D. Randomised controlled trial comparing problem solving treatment with amitriptyline and placebo for major depression in primary care. BMJ. 1995;310:441-445.

8. Katon W, Von Korff M, Lin E, et al. Stepped collaborative care for primary care patients with persistent symptoms of depression: a randomized trial. Arch Gen Psychiatry. 1999;56:1109-1115.

9. Tutty S, Simon G, Ludman E. Telephone counseling as an adjunct to antidepressant treatment in the primary care system. Eff Clin Pract. 2000;4:170-178.

10. Simon GE, VonKorff M, Rutter C, Wagner E. Randomised trial of monitoring, feedback, and management of care by telephone to improve treatment of depression in primary care. BMJ. 2000;320:550-554.

11. Williams JW Jr, Barrett J, Oxman T, et al. Treatment of dysthymia and minor depression in primary care: a randomized controlled trial in older adults. JAMA. 2000;284:1519-1526.

12. Hunkeler EM, Meresman JF, Hargreaves WA, et al. Efficacy of nurse telehealth care and peer support in augmenting treatment of depression in primary care. Arch Fam Med. 2000;9:700-708.

13. Goldberg HI, Wagner EH, Fihn SD, et al. A randomized controlled trial of CQI teams and academic detailing: Can they alter compliance with guidelines? Jt Comm J Q Improv. 1998;24:130-142.

14. Worrall G, Angel J, Chaulk C, Robbins M. Effectiveness of an educational strategy to improve family physicians' detection and management of depression: a randomized controlled trial. Can Med Assoc J. 1999;161:37-40. 
15. Miranda J, Munoz R. Intervention for minor depression in primary care patients. Psychosom Med. 1994;56:136-142.

16. Callahan CM, Hendrie HC, Dittus RS, Brater DC, Hui SL, Tierney WM. Improving treatment of late life depression in primary care: a randomized clinical trial. J Am Geriatr Soc. 1994;42:839-846.

17. Thompson C, Kinmonth AL, Stevens L, et al. Effects of a clinicalpractice guideline and practice-based education on detection and outcome of depression in primary care: Hampshire Depression Project randomised controlled trial. Lancet. 2000;355:185-191.

18. Carr VJ, Lewin TJ, Reid ALA, Walton JM, Faehrmann C. An evaluation of the effectiveness of a consultation-liaison psychiatry service in general practice. Aust N Z J Psychiatry. 1997;31:714-725.

19. Mynors-Wallis L, Davies I, Gray A, Barbour F, Gath D. A randomised controlled trial and cost analysis of problem-solving treatment for emotional disorders given by community nurses in primary care. $\mathrm{Br}$ Psychiatry. 1997;170:113-119.

20. Teasdale JD, Fennel MJV, Hibbert GA, Amies PL. Cognitive therapy for major depressive disorder in primary care. $\mathrm{Br} J$ Psychiatry. $1984 ; 144: 400-406$

21. Brown JB, Shye D, McFarland BH, Nichols GA, Mullooly JP, Johnson RE. Controlled trials of CQI and academic detailing to implement a clinical guideline for depression. Jt Comm J Q Improv. 2000;26:39-54.

22. Tiemens BG, Ormel J, Jenner JA, et al. Training primary-care physicians to recognize, diagnose and manage depression: Does it improve patient outcomes? Psychol Med. 1999;29:833-845.

23. Lin EHB, Simon GE, Katon WJ, et al. Can enhanced acute-phase treatment of depression improve long-term outcomes? A report of randomized trials in primary care. Am J Psychiatry. 1999; 156:643-645.

24. Sherbourne CD, Wells KB, Duan N, et al. Long-term effectiveness of disseminating quality improvement for depression in primary care. Arch Gen Psychiatry. 2001;58:696-703.

25. Rost K, Nutting PA, Smith J, Werner JJ. Designing and implementing a primary care intervention trial to improve the quality and outcome of care for major depression. Gen Hosp Psychiatry. 2000;22:66-77.

26. Wagner EH, Austin BT, Von Korff M. Organizing care for patients with chronic illness. Milbank Q. 1996;74:511-544.

27. Von Korff M, Gruman J, Schaefer J, Curry SJ, Wagner EH. Collaborative management of chronic illness. Ann Intern Med. 1997; 127:1097-1102.

28. Rost K, Nutting P, Smith JL, Elliott CE, Dickinson M. Managing depression as a chronic disease: a randomised trial of ongoing treatment in primary care. BMJ. 2002;325:934-939.

29. Oxman TE, Dietrich AJ, Williams JW, Jr, Kroenke K. A three-component model for reengineering systems for the treatment of depression primary care. Psychosomatics. 2002;43:441-450.

30. Rost K, Nutting P, Smith J, Werner J, Duan N. Improving depression outcomes in community primary care practice: a randomized trial of the QuEST intervention. J Gen Intern Med. 2001;16:143-149.

31. Diagnostic and Statistical Manual of Mental Disorders: DSM-III-R. Arlington, Va: American Psychiatric Association; 1987.

32. Schoenbaum M, Unutzer J, Sherbourne C, et al. Cost-effectiveness of practice-initiated quality improvement for depression: results of a randomized, controlled trial. JAMA. 2001;286:1325-1330.

33. Lave JR, Frank RG, Schulberg HC, Kamlet MS. Cost-effectiveness of treatments for major depression in primary care practice. Arch Gen Psychiatry. 1998;55:645-651.

34. Simon GE, Manning WG, Katzelnick DJ, Pearson SD, Henk HJ, Helstad CP. Cost-effectiveness of systematic depression treatment for high utiliz ers of general medical care. Arch General Psychiatry. 2001;58:181-187.

35. Simon GE. Cost-effectiveness of a collaborative care program for primary care patients with persistent depression. Am J Psychiatry. 2001:158:1638-1644
36. Gibbons RD, Hedeker D. Application of random-effects probit regression models. J Consult Clin Psychol. 1994;62:285-296.

37. Gold MR, Siegel JE, Russell LB, Weinstein MC. Cost-Effectiveness in Health and Medicine. Oxford: Oxford University Press; 1996.

38. Drummond MF, Jefferson TO. Guidelines for authors and peer reviewers of economic submissions to the BMJ. The BMJ Economic Evaluation Working Party. BMJ. 1996;313:275-283.

39. Brazier J, Usherwood T, Harper R, Thomas K. Deriving a preferencebased single index from the UK SF-36 health survey. J Clin Epidemiol. 1998;51:1115-1128

40. Littell RC, Milliken GA, Stroup WW, Wolfinger RD. SAS System for Mixed Models. Cary, NC: SAS Institute, Inc; 1996.

41. Fairclough DL. Design and Analysis of Quality of Life Studies in Clinical Trials. New York, NY: Chapman \& Hall/CRC; 2002.

42. Stewart J. Calculus: Concepts and Contexts. 2nd ed. Pacific Grove, Calif: Brooks/Cole; 2001.

43. Wolff N, Helminiak TW, Tebes JK. Getting the cost right in cost-effectiveness analyses. Am J Psychiatry. 1997; 154:736-743.

44. Duan N. Smearing estimate: a nonparametric retransformation method. J Am Stat Assoc. 1983;78:605-610.

45. Manning WG. The logged dependent variable, heteroscedasticity, and the retransformation problem. J Health Econ. 1998;17:283-295.

46. Bureau of Labor Statistics. Consumer Price Indexes. 2002. Available at http://www.bls.gov/cpi/.

47. 2000 Red Book. Montvale, NJ; Medical Economics Co, 2000.

48. Briggs $\mathrm{AH}$, Wonderling DE, Mooney CZ. Pulling cost-effectiveness analysis up by its bootstraps: a non-parametric approach to confidence interval estimation. Health Econ. 1997:6:327-340.

49. Hunink MG, Bult JR, de Vries J, Weinstein MC. Uncertainty in decision models analyzing cost-effectiveness: the joint distribution of incremental costs and effectiveness evaluated with a nonparametric bootstrap method. Med Decis Making. 1998;18:337-346

50. Laupacis A, Feeny D, Detsky AS, Tugwell PX. How attractive does a new technology have to be to warrant adoption and utilization? Tentative guidelines for using clinical and economic evaluations. Can Med Assoc J. 1992;146:473-481.

51. Pyne JM, Rost KM, Zhang M, Williams DK, Smith J, Fortney J. Costeffectiveness of a primary care depression intervention. J Gen Intern Med. 2003;18:432-441.

52. Goldman L, Weinstein M, Goldman PA, Williams LW. Cost-effectiveness of HMG-COA reductase inhibition for primary and secondary prevention of coronary heart disease. JAMA. 1991;265:1145-1151.

53. Kaplan RM, Anderson JP. A general health policy model: update and applications. Health Serv Res. 1988; 23:203-235.

54. Valenstein M, Vijan S, Zeber JE, Boehm K, Buttar A. The cost-utility of screening for depression in primary care. Ann Intern Med. 2001; 134:345-360.

55. Unutzer J, Katon WJ, Russo J, et al. Willingness to pay for depression treatment in primary care. Psychiatr Serv. 2003;54:340-345.

56. National Institutes of Health, National Institute of Mental Health. Bridging Science and Service - A Report by the National Advisory Mental Health Council's Clinical Treatment and Services Research Workgroup. Washiington, DC: National Institutes of Health; 1999.

57. Katon W, Russo J, Von Korff M, et al. Long-term effects of a collaborative care intervention in persistently depressed primary care patients. J Gen Intern Med. 2002;17:741-748.

58. Katzelnick DJ, Simon GE, Pearson SD, et al. Randomized trial of a depression management program in high utilizers of medical care. Arch Fam Med. 2000;9:345-351. 